\title{
Seismic interferometry applied to local fracture seismicity recorded at Planchón-Peteroa Volcanic Complex, Argentina-Chile
}

\author{
J.A. Casas ${ }^{a, *}$, D. Draganov ${ }^{b}$, G.A. Badi ${ }^{c}$, M.C. Manassero ${ }^{c}$, V.H. Olivera Craig ${ }^{c}$, L. Franco Marín ${ }^{d}$, \\ M. Gómez ${ }^{\mathrm{e}}$, E. Ruigrok ${ }^{\mathrm{f}, \mathrm{g}}$ \\ ${ }^{\text {a }}$ Facultad de Ciencias Astronómicas y Geofísicas, Universidad Nacional de La Plata, CONICET, Argentina \\ ${ }^{\mathrm{b}}$ Department of Geoscience and Engineering, Delft University of Technology, the Netherlands \\ ${ }^{\mathrm{c}}$ Facultad de Ciencias Astronómicas y Geofísicas, Universidad Nacional de La Plata, Argentina \\ ${ }^{\mathrm{d}}$ Observatorio Volcanológico de los Andes del Sur (OVDAS-SERNAGEOMIN), Chile \\ ${ }^{\mathrm{e}}$ International Center for Earth Sciences, Comision Nacional de Energia Atómica, Argentina \\ ${ }^{\mathrm{f}}$ Department of Earth Sciences, Utrecht University, the Netherlands \\ ${ }^{\mathrm{g}} \mathrm{R} \& D$ Seismology and Acoustics, Royal Netherlands Meteorological Institute, the Netherlands
}

\section{A R T I C L E I N F O}

\section{Keywords:}

Seismic interferometry by autocorrelations

Planchón-Peteroa Volcanic Complex

Fracture seismicity

Subsurface reflectors

\begin{abstract}
A B S T R A C T
Although the Planchón-Peteroa Volcanic Complex (PPVC) has undergone many hazardous eruptions, only a small number of geological, geochemical, and geophysical studies have been performed to describe this active volcanic system. In order to characterize the subsurface structures present at the PPVC, we applied seismic interferometry to fracture seismicity originating in this volcanic complex and along active geologic faults located nearby. We utilized seismic data recorded by two arrays of stations deployed in Argentina and Chile. Nine of these stations (three in Chile and six in Argentina) recorded data simultaneously and were used for this application. Only seismic events with energy arriving (sub) vertically to the stations were chosen for processing. According to the magnitude and the location of the selected seismic events, relocated seismic sources were used for the Chilean stations while, for the Argentine stations, only seismic sources located near that array were used. We obtained seismic evidence of the location of the subsurface reflectors underneath each station using zero-offset reflection responses retrieved from seismic interferometry by autocorrelation of (time windows extracted from) the selected seismic events. Then, applying a comparative analysis between the seismic results and the available geological information, we imaged the shallow subsurface of the area enclosed by the Chilean stations, and also by the Argentine stations. The results are consistent with the available geological information, provide accurate depth values for several subsurface discontinuities, indicate areas of higher heterogeneity, and support the emplacement of a magma body at $\sim 4 \mathrm{~km}$ depth from the surface. This work shows the first application of a novel variation of seismic interferometry based on autocorrelations to local-earthquake data recorded in a volcanic area.
\end{abstract}

\section{Introduction}

Along the western continental margin of South America, the convergence between the Nazca and the South-American plates has caused the uplift of the Andes. The subduction of the Nazca plate below the continental plate has developed the active volcanic chain situated along much of this deformation zone. This volcanic chain is segmented in four well-constrained volcanic zones: Northern Volcanic Zone (between latitudes $2^{\circ} \mathrm{N}$ and $\left.5^{\circ} \mathrm{S}\right)$, Central Volcanic Zone $\left(14^{\circ} \mathrm{S}-28^{\circ} \mathrm{S}\right)$, Southern Volcanic Zone (SVZ, $33^{\circ} \mathrm{S}$ and $46^{\circ} \mathrm{S}$ ), and Austral Volcanic Zone $\left(49^{\circ} \mathrm{S}\right.$ $55^{\circ} \mathrm{S}$ ). The Transitional Southern Volcanic Zone (TSVZ) is located between latitudes $34.5^{\circ} \mathrm{S}$ and $37^{\circ} \mathrm{S}$ (López-Escobar et al., 1995) in the
Southern Volcanic Zone (see Fig. 1). In the TSVZ, the angle of subduction ranges between $30^{\circ}$ and $35^{\circ}$ approximately, allowing the genesis of magmas at $100 \mathrm{~km}-200 \mathrm{~km}$ depth (Gill, 1981). The active tectonics have caused NW-SE and NE-SW fault systems, which enable ascent and emplacement of magma causing spatial control of calderas, stratovolcanoes, and geothermal activity, and as a consequence, the genesis of the Planchón-Peteroa Volcanic Complex -PPVC (Cembrano and Lara, 2009). The PPVC is constituted by three volcanic structures, i.e., Azufre, Planchón, and Peteroa volcanoes (see location in Fig. 4). The Peteroa is the current active volcano of this volcanic complex; it has been originated by volcanic activity concentrated in several scattered vents (Tormey et al., 1989; Haller et al., 1994). Historical activity

\footnotetext{
* Corresponding author.

E-mail addresses: acasas@fcaglp.unlp.edu.ar, casasaugusto@gmail.com (J.A. Casas).
} 


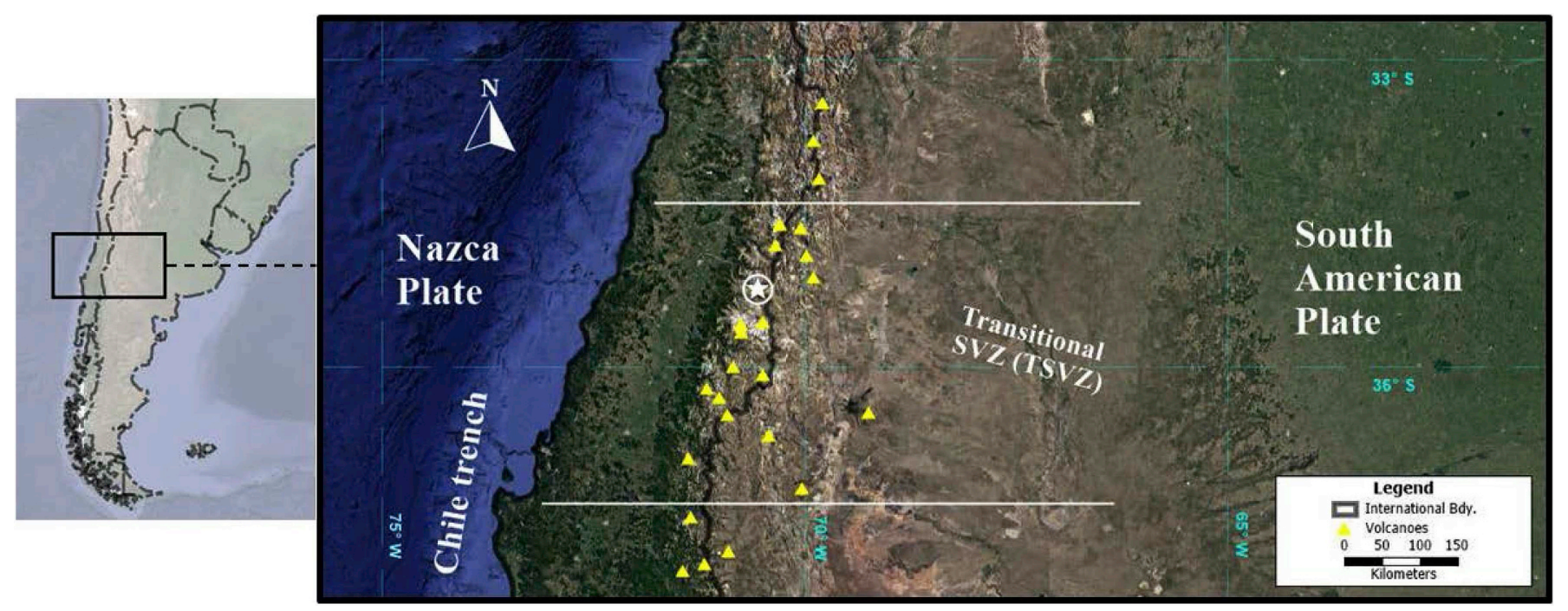

Fig. 1. Location of the study area (left), and tectonic setting, location of the Transitional South Volcanic Zone (TSVZ), and the developed volcanic edifices (right). A white star indicates the Planchón-Peteroa Volcanic Complex (PPVC).

records of Peteroa volcano expose about twenty eruptive events with VEI $\leq 4$ (Haller and Risso, 2011). Based on analyses of the volcanic deposits in the area of the PPVC and those ejected during the ash pulses occurred between August 2010 and July 2011, Naranjo (2012) characterized the observed volcanic activity as indicating a system reactivation. Aguilera et al. (2016) performed analyses of fall deposits and geochemical samples from fumaroles and crater lakes associated to the 2010-2011 eruption period; they integrated this information with eruptive records and satellite data, suggesting two possible mechanisms for the transfer of heat and mass from buried hydrothermal-magmatic reservoirs: the development or reactivation of cracks after the Mw 8.8 Maule earthquake in February 2010, or an instability produced by a reduction of fluid pressure within a shallow reservoir which caused a rupture of the seal zone confining an underlying magma chamber, causing phreatic eruptions.

Based on the geological information available for the area of the PPVC and through geochemical analyses of fluid discharges located at the summit of Peteroa volcano and its surroundings, in addition to remote sensing studies, Benavente Zolezzi (2010) proposed a conceptual model for the first $10 \mathrm{~km}$ of the subsurface (see Fig. 2). This model shows highly heterogeneous zones caused by mixing of waters, boiling, and liquid-gas segregation; it also indicates the emplacement of a magma body at $\sim 4 \mathrm{~km}$ depth in the eastern flank of the volcano. Benavente Zolezzi (2010) proposed that the interaction of a shallow water reservoir with rocks heated by the shallowest part of the magma chamber (about $4 \mathrm{~km}$ depth) could explain the periods of volcanic unrest. Tassi et al. (2016) also analyzed the fluid discharges in the area for the period 2010-2015; the composition of the samples would suggest the presence of two magma batches emplaced at different depths: a shallow dacitic reservoir and a deeper basaltic reservoir. The eastern flank of the Peteroa volcano is characterized by bubbling pools and a shallow aquifer, which is fed by a melting ice cap and infiltrating groundwater. Gases from the bubbling pools are characterized by a small magmatic fluid contribution, which could suggest a proximity to a magma reservoir. The likely presence of magma approaching a subsurface saturated by water warrants the necessity of studying the area.

Currently, the monitoring of the PPVC is operated by the Observatorio Volcanológico de los Andes del Sur (OVDAS - SERNAGEOMIN, Chile) which analyze seismic records, GNSS data, and SO2 measurements. The Argentine side, i.e., the eastern flank, of Peteroa is monitored by two seismic stations, real-time camera observations, and SO2 and diffuse CO2 measurements (Raponi et al., 2017; Agusto et al., 2017). This information is available to the local authorities for the development of strategies during periods of volcanic instability. Seismic

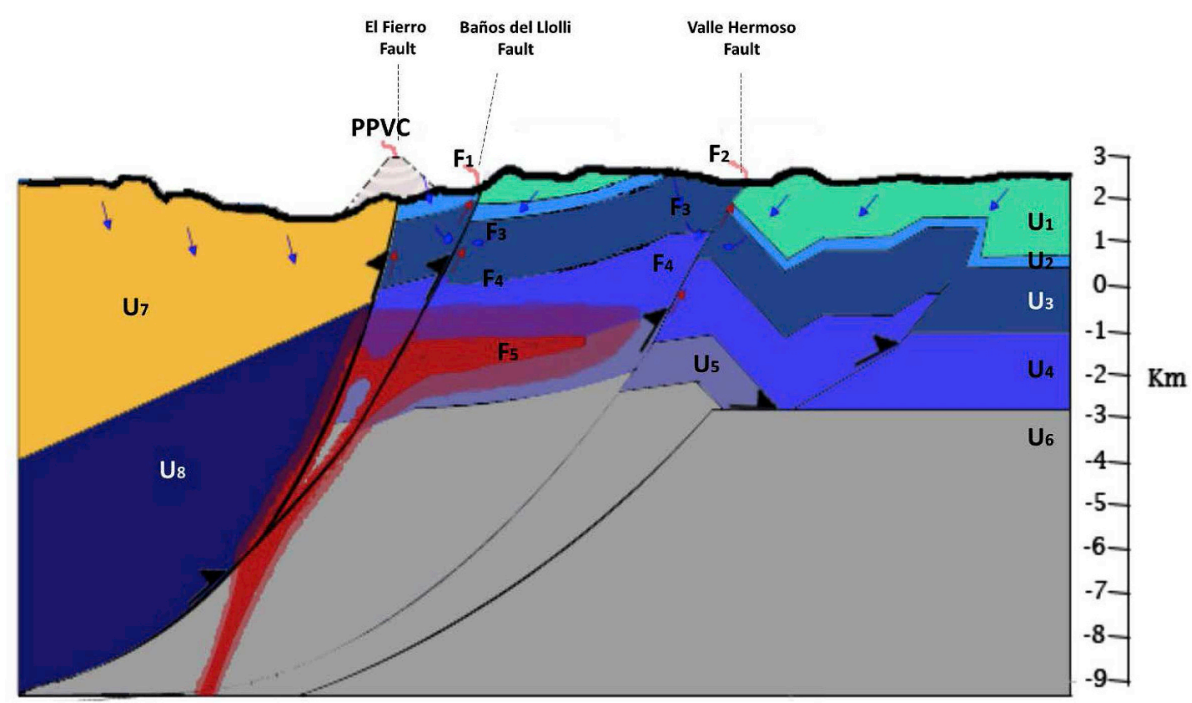

Fig. 2. Conceptual subsurface model for the area of the PPVC. Depth values are related to the mean sea level. U: Lithological Unit. F: Geological Feature. $\mathrm{U}_{1}$ : Vega Negra. $U_{2}$ : Gypsum layer. $U_{3}$ : Valle Grande. $U_{4}$ : Lotena. $\mathrm{U}_{5}$ : Grupo Cuyo? $\mathrm{U}_{6}$ : pre-Jurassic Basement? $\mathrm{U}_{7}$ : Abanico. $\mathrm{U}_{8}$ : Basement. $\mathrm{F}_{1}$ and $\mathrm{F}_{2}$ : Fumaroles. $\mathrm{F}_{3}$ : Zone of waters blending. $\mathrm{F}_{4}$ : Water boiling and liquid-gas segregation. $\mathrm{F}_{5}$ : Magma body. Modified from Benavente Zolezzi (2010). 
data processing provides knowledge of the structures and the physical processes occurring in the subsurface. Knowledge contributes to the better understanding of this volcanic complex, thus improving decisions and future strategies.

Casas et al. (2014) concluded that, during 2012, Peteroa volcano showed seismic activity with continuous low-energy signals and a large number of transient signals with slightly higher energy. They identified long-period tremor, events associated with fractures, and long-period events related to degassing and hydrothermal phenomena. Based on the large number of identified seismic events per day, the Peteroa active volcanic system showed sustained energy release. The identified and localized events constitute a frame for the development of this work.

New techniques for subsurface characterization and monitoring of dynamic processes have been developed in the last 50 years. One of these techniques is seismic interferometry (SI) - an innovative methodology that can greatly improve the resolution of seismic images compared to classical seismic images (Schuster, 2009). SI is a datadriven method that retrieves a seismic response between two seismic sensors from their seismic records using correlation, coherence, convolution, or deconvolution (e.g., Wapenaar et al., 2008; Vasconcelos and Snieder, 2008a,b; Nakata et al., 2011; Wapenaar et al., 2011). This method is now regularly used in exploration and global seismology with active and/or passive sources, i.e., with artificial sources (dynamite, vibroseis, sledge hammer, etc.) or natural sources (earthquakes, anthropogenic noise, ocean microseisms, etc.). SI basically redatums the wavefields generated by these sources to retrieve virtual-source responses as if one of the sensors were a source. Moreover, SI allows one to extract subsurface information from complicated or random wavefields (Sens-Schönfelder and Wegler, 2006; Brenguier et al., 2008; Schuster, 2009), after which the extracted information can be used with traditional seismic methods.

The work of Claerbout (1968) is part of the foundation upon which SI was developed. Claerbout (1968) showed that the autocorrelation of the plane-wave transmission response of a layered subsurface, recorded at the Earth surface, retrieves the reflection response of a virtual source co-located at the receiver (see also Wapenaar et al., 2010). SI by autocorrelation is a very powerful and robust tool, so it is applied with field data in different ways. For example, it was applied to teleseismic and global phases (i.e., waves that propagate across the mantle and mantle + core, respectively, before reaching a station) for crustal imaging on a regional scale (Ruigrok and Wapenaar, 2012, Nishitsuji et al., 2016a,b), to P-waves from microearthquakes for imaging the shallow subsurface of a volcano (Kim et al., 2017), and to ambientnoise measurements (Gorbatov et al., 2013; Boullenger et al., 2014; Oren and Nowack, 2017).

By application of SI by autocorrelation, reflection responses are retrieved which are further used to image the P-wave reflectivity of the shallow subsurface underneath each of the deployed stations. This information contributes to the detection of key features of the subsurface (i.e., the depth of several previously proposed discontinuities, areas of higher heterogeneity, and a zone of supposed magma emplacement), which is essential for an appropriate explanation of the volcanic processes occurring in the area and for reducing the ambiguity in previous studies.
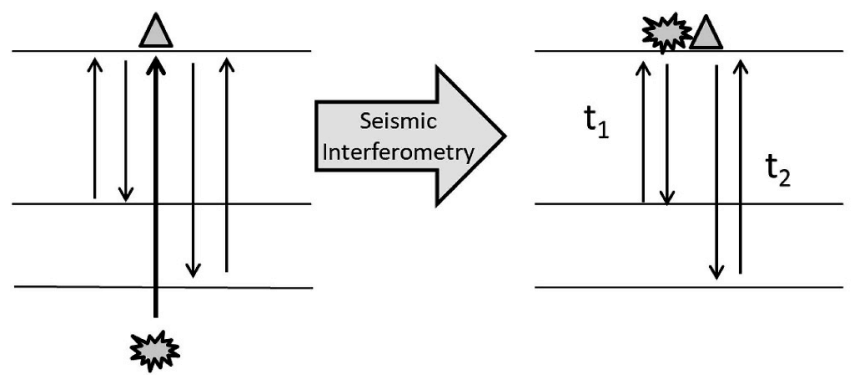

\section{Seismic interferometry by autocorrelation}

SI by autocorrelation can be used to obtain information about the reflectivity of the subsurface below stations located at the surface. The relation

$$
\begin{aligned}
& \sum_{\text {sources }}\left\{\left[T\left(X_{A},-t\right) * s_{i}(-t) * T\left(X_{A}, t\right) * s_{i}(t)\right]\right. \\
& \left.\quad \otimes[s(-t) * s(t)]_{i}\right\} \approx-R\left(X_{A},-t\right)+\delta(t)-R\left(X_{A}, t\right)
\end{aligned}
$$

(equations (36) and (37) from Wapenaar and Fokkema (2006) after modification for autocorrelation) establishes that the reflection response $R\left(X_{A}, t\right)$ can be obtained at station "A" located (at $X_{A}$ ) at the top of the subsurface of interest by autocorrelating a plane-wave transmission wavefield $T\left(X_{A}, t\right)$ propagated through a horizontally layered subsurface. The operator “*” denotes convolution, “ $\otimes$ " indicates deconvolution, and $\delta(t)$ is the Dirac's delta function. The sources are characterized by a "source time function" (STF) (Yilmaz, 2001). The STF is a transient waveform with a finite duration, which describes the energy release at the rupture as a function of time. Then, the factor $[s(-t) * s(t)]_{i}$ is the Autocorrelated Source Time Function (ASTF), which is estimated (see Section 4.b. Processing) to deconvolve the true ASTF for each employed source $\left(s_{i}\right)$.

In the light of the theory and applications in Wapenaar (2003) and Ruigrok and Wapenaar (2012), we use the fracture seismicity recorded by stations located in the area of PPVC, which might have been caused by volcanic processes. Equation (1) requires sources inside through the whole stationary-phase area (i.e., the Fresnel zone) for the accurate retrieval of $R\left(X_{A}, t\right)$. Even though most of the seismic variables (e.g., amount of seismic events, their magnitudes, and source properties, even sources caused by volcanic activity) present a wide range of values at convergence subduction-type zones, the distribution of sources in space and time does not completely cover the stationary-phase area. Therefore, events inducing waves with nearly vertical incidence at a station are selected. Because of the choice of incidence energy we make, the vertical component of the records are a good estimate of the P-wave transmission response. We retrieve the reflection response (from here on, $R_{v}\left(X_{A}, t\right)$ ) of a virtual source that radiates energy (sub) vertically downwards, co-located with the station at the surface.

Fig. 3 presents a cartoon illustrating the methodology applied in this research. A source in the subsurface releases energy that propagates towards a surface station and thus reflects at the surface before propagating in the subsurface again. In such a way, seismograms are shaped by the arrival of direct waves followed by reverberated waves. The latter are energy that underwent multiple reflections/scattering on discontinuities and heterogeneities in the subsurface or at the surface before arriving at a station. SI isolates these arrivals by removing the paths preceding them (e.g., the direct waves) to obtain information about subsurface reflectors.

\section{Data}

We use seismic data recorded by stations deployed in Argentina and Chile (see Fig. 4). The Argentine stations were deployed by the MalARRgue project (Ruigrok et al., 2012; Nishitsuji et al., 2014), whose main goal was to image and monitor the subsurface below the Malargüe

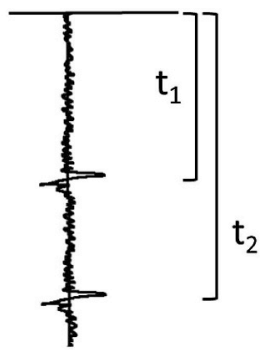

Fig. 3. Effect of application of seismic interferometry by autocorrelation to normal-incidence events in an idealized horizontally layered subsurface. $t_{i}$ stands for two-way travel time to the displayed reflectors. The autocorrelation eliminated the common travel path, in this case the direct wave (left), to turn the reverberations (left) into reflections (right). 

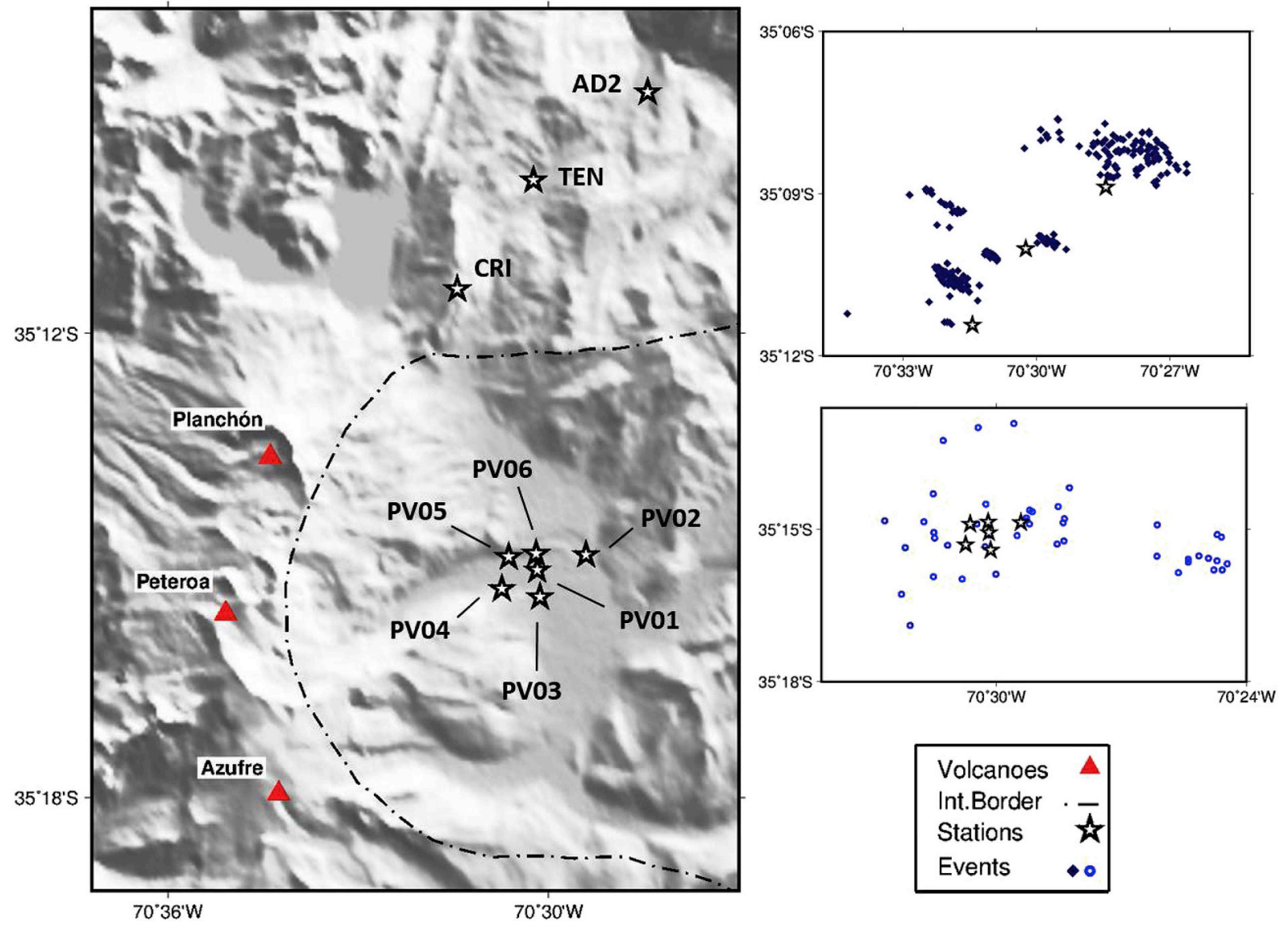

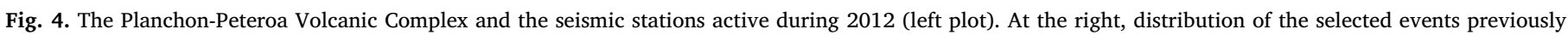
relocated close to the OVDAS stations (solid diamonds), and those selected events located close to the PV-array (empty circles).

region, Mendoza Province, Argentina. For this project, 38 seismic stations were installed; the data from six of these stations were used in this study (in text, the PV-array). The stations used here were located on the eastern (Argentine) flank of Peteroa volcano from January 2012 to January 2013. They were equipped with $2-\mathrm{Hz} 3$-component seismic sensors (Sercel L-22).

Another source of data is provided by the Red Nacional de Vigilancia Volcánica (RNVV, Chile) which is maintained by the OVDAS. The RNVV runs a seismic network on the Chilean side of Peteroa volcano since 2010. OVDAS has a permanent array of broadband (30-s period) 3-component Guralp and Trillium sensors. Three of the OVDAS stations that recorded data simultaneously with the Argentine stations were used for this research.

\section{Application and Results}

\subsection{Pre-processing}

In order to apply SI by autocorrelation to P-wave seismic energy, the propagating waves have to arrive vertically (or sub-vertically) at the vertical component of a station. In the case of a subsurface composed of horizontal homogeneous layers, the sources have to be located exactly below the station to get a reliable measurement of the propagation time between the subsurface layers and the station at the surface. In volcanic areas, the heterogeneity of the subsurface is sufficiently high so that the source location is not a critical parameter for the P-wave transmission response to be accurately estimated by the vertical-component records (Fan and Snieder, 2009). Therefore, the selection of sources located near the stations is a satisfactory condition for the application of the proposed methodology. Still, reduced uncertainties in source locations are important to select properly the events to be processed.
The location of seismic events is of great importance to understand active magmatic systems and to determine the extent and evolution of source regions of magmatic energy (Chouet, 2003). Event location is a fundamental component of the conventional activities of worldwide volcano observatories. In particular, since 2010, the OVDAS has applied seismic monitoring on the Chilean side of the PPVC; this information is recounted on public-domain activity reports and on internal-use seismic catalogues.

Independently, based on data recorded by the temporal stations deployed by the MalARRgue Project, Casas et al. (2014) identified and located seismicity from fracturing that originated at PPVC or in active geologic faults located nearby this volcanic complex. Then, based on the location of these seismic sources, we select those suited for application of SI by autocorrelation to the Argentine seismic stations.

Each one of the deployed seismic arrays is characterized by poor azimuthal coverage, leading to high uncertainties in the event location. Therefore, in order to obtain a better estimate of the source locations, Olivera Craig (2018) applied a re-location procedure to the seismicity from fracturing recorded by both arrays in 2012 . The relocation scheme was performed by a double-difference algorithm (i.e., HypoDD -Waldhauser and Ellsworth, 2000), based on a velocity model modified from the one developed by Bohm et al. (2002). Their results showed that the sources are distributed in three groups, which are related to specific geological settings in the area, in particular to the fault system responsible for the genesis of this volcanic complex. One of the three groups is close to the Chilean stations, while no relocated sources result near the Argentine stations. Thus, if the fracture events are to be used with SI by autocorrelation, only one of these groups can be used to retrieve the reflection responses at the Chilean stations.

We select the events close to the stations for further application of SI by autocorrelation; this selection was performed by estimation of the 
angle of incidence for each event at each of the stations in consideration of P-wave energy in an effective homogeneous-velocity medium, i.e., one whose response in propagation time is analogous to that of the actual heterogeneous subsurface. Provided the errors on the location procedure and the depth of the sources (i.e., peak horizontal and vertical errors of 4.02 and $3.35 \mathrm{~km}$, respectively), angles of incidence less than $20^{\circ}$ at a station were accepted for retrieval of the reflection response using SI by autocorrelation. Fig. 4 shows the distribution of the selected relocated events (solid diamonds); this figure also displays the selected seismic events (with circles) whose location was calculated using only the PV-array (Casas et al., 2014). The latter sources were characterized by a lower energy, so they could not be identified on the OVDAS stations. One should note that the closer to the array, the more accurate the location (Husen and Hardebeck, 2010). Thus, for the sources relatively close to the stations of the PV-array, the location uncertainty is also relatively low.

\subsection{Processing}

We retrieve reflection responses at each of the stations through the application of several processing steps to the vertical-component records of the selected sources. The retrieval procedure comprises an instrument response deconvolution, frequency band-pass filtering, extraction of the time windows to be further processed, energy normalization, autocorrelation, Source Time Function (STF) estimation and deconvolution, and linear stacking (see workflow diagram in Fig. 5).

Seismometers are sensitive to vibrations within a specific range of frequencies, which defines their instrument-response curve. Thus, we apply an instrument-response deconvolution. Short-period and broadband stations have been utilized. The broadband sensors (Guralp 6TD) have a planar response between frequencies $0.033 \mathrm{~Hz}$ and $20 \mathrm{~Hz}$, while the short-period (Sercel L22) sensors have a flat response in velocity above $2 \mathrm{~Hz}$. Despite the corner frequency of $2 \mathrm{~Hz}$ for the latter, accurate amplitudes are still obtained down to $0.1 \mathrm{~Hz}$, given that the data is corrected for the instrument response (Weemstra et al., 2017).

Based on the comparison of spectral amplitudes of the signal and the background noise, we select the frequency range for processing at each station. Time intervals for background noise and for signal plus background noise are defined per event. For each event, the background noise window corresponds to the $10 \mathrm{~s}$ of seismic data previous to the arrival of the P-wave energy; the signal-plus-background-noise window corresponds to the seismic data between the P-wave arrival and the $\mathrm{S}$ -

Instrument response deconvolution

\section{$\downarrow$}

Frequency band-pass filtering

$$
\downarrow
$$

Pre-processing

P-wave coda extraction

$$
\text { Energy normalization }
$$

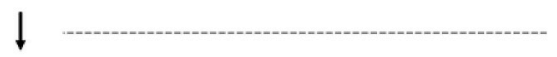

Autocorrelation

I

Source Time Function (STF)

estimation and deconvolution

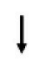

Linear stacking

Fig. 5. Pre-processing and processing steps applied to the vertical-component records of previously selected events for each of the used stations. wave arrival. The average signal (noise) spectral amplitudes are estimated for every station (see Fig. 6a, for the PV06 station). As the SNR is similar for the considered events, we average the SNR over events and determine per station the frequency band in which the contribution of the signal is greater than that of the noise; we then use this frequency range further for processing. Table 1 shows the frequency range selected at each of the stations.

Incoherent noise is largely suppressed when applying SI (e.g., Wapenaar et al., 2008; Schuster, 2009). Nevertheless, including relatively noisy data in the processing requires the inclusion of a greater number of records, so the seismic energy related to subsurface reflectors is enhanced. The selection of the frequency range at each of the stations is based on the general spectral characteristics of the group of events selected for every station. If SNR of the events is still low after filtering, we discard these events. As an example, Fig. $6 \mathrm{~b}$ shows the events finally utilized in the retrieval for the PV06 station.

When the aim is to retrieve arrivals from seismic data that does not comply with the requirement to have separate recordings of P- and Swave sources for utilization of the approximate SI relations (Wapenaar and Fokkema, 2006; Draganov et al., 2007), artifacts would be retrieved due to cross-talk from correlations between different types of waves (P-, S-, and surface waves). Because of this, a step for suppressing cross terms is required. As we aim to retrieve P-wave reflections, suppression of cross-talk could easily be achieved by selecting for further processing only time windows starting just before the direct P-wave arrival and ending before the arrival of the direct $S$-wave, i.e., we use the primarily $\mathrm{P}$-wave direct arrival and the P-wave coda.

Equation (1) assumes that the sources have the same energy level. If this is not the case, in the summation process information from weaker sources would be lost. Therefore, normalizing data will equalize the contribution from each event recorded by a station to the same energy level. To achieve this, we apply energy normalization, which scales the data of a selected Pwave window by the vertical-energy flux in that P-wave window.

We aim to retrieve reflections by applying SI by autocorrelation to selected time windows of events identified as having (sub) vertical incidence of the P-wave energy to a station. In the application of Equation (1), a first approximation of the zero-offset reflection response is obtained by (after autocorrelation) the deconvolution of the estimated ASTF in a process that involves a prior analysis of its time-frequency characteristics. We estimate the ASTF per event by taking the times relevant to the main zero-lag lobe. Fig. 7 shows an example of an estimated ASTF and the effect of its deconvolution for one of the events recorded by the PV02 station. As a result of the deconvolution procedure, deconvolved retrieved arrivals close to time $0 \mathrm{~s}$ (i.e., the $0 \mathrm{~s}$ main lobe and its contiguous monotonously decreasing secondary lobes) are interpreted as most likely artifacts. Because of this, before summation, we taper to zero the times earlier than $0.1 \mathrm{~s}$.

The stationary-phase region (or Fresnel zone) comprises (in our case) a part of a layer/structure from which an arrival in the autocorrelated trace from a selected seismic event will exhibit very small to no time difference among autocorrelated selected seismic events. The final step of Equation (1) is summation over the sources. This process results in constructive interference inside the stationary-phase zone (due to the little to no time difference between events) and destructive interference outside it (Snieder, 2004), thus arrivals from real reflectors are enhanced (Schuster, 2009).

\subsection{Results}

The application of the workflow described in the previous sections (see Fig. 5) allows us to identify the two-way travel time of the P-wave reflection energy of shallow-subsurface reflectors underneath each of the stations deployed in the area of Peteroa volcano. The heterogeneous nature of the subsurface in the PPVC might blur weak reflection arrivals produced by low-impedance contacts as well as attenuated scattered waves (e.g., diffracted waves). Therefore, in order to obtain a reliable 
(a)
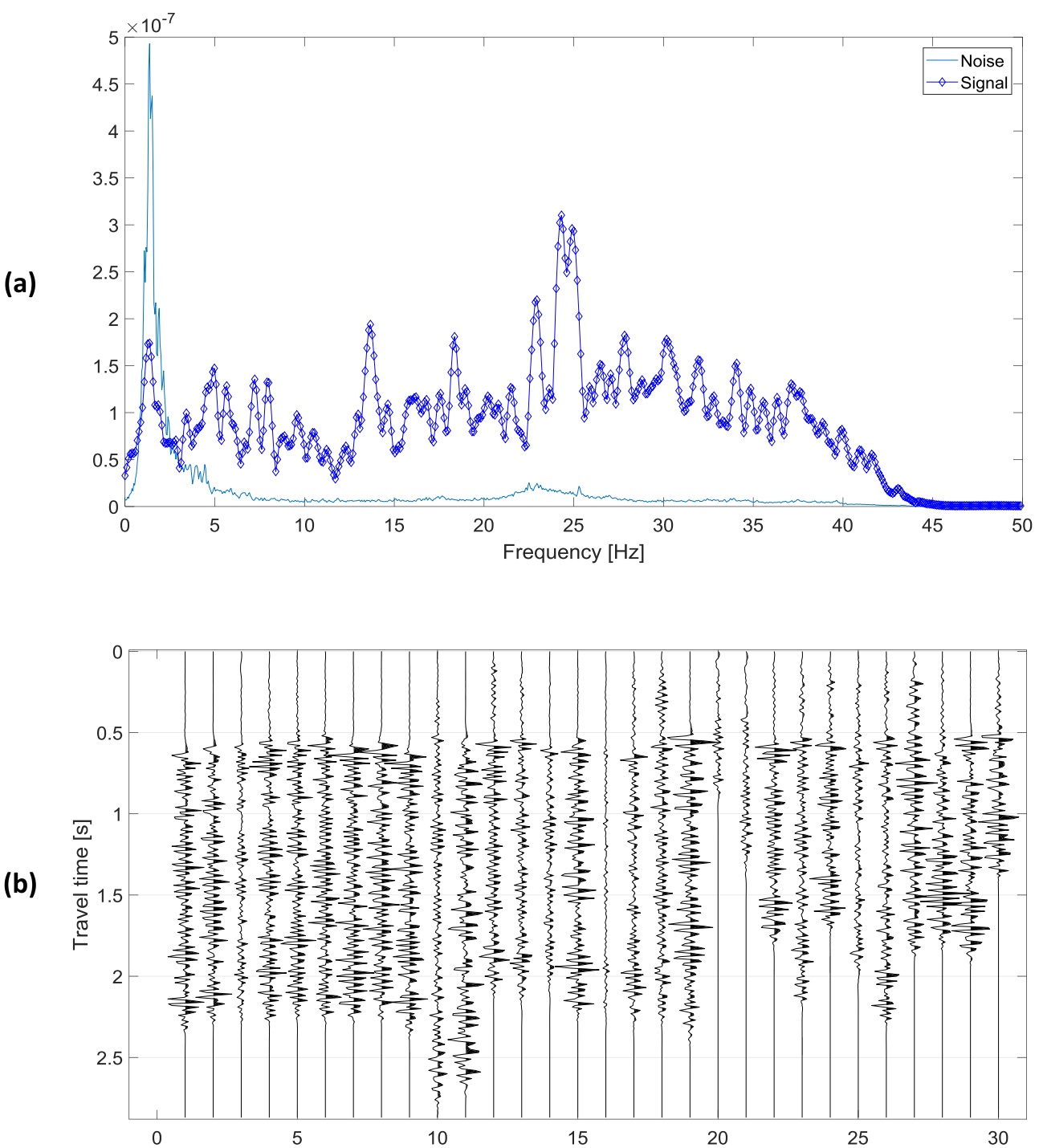

Fig. 6. (a) Average amplitude spectrum of the background noise and signal plus background noise for the P-wave energy of the vertically incident events at the station PV06. (b) Best SNR records for the station used in (a). The spectral amplitude pick at $\sim 2 \mathrm{~Hz}$ is caused by the volcanic tremor present in the area (Casas et al., 2014).

Table 1

Station location, altitude, and selected processing frequency range.

\begin{tabular}{lllll}
\hline $\begin{array}{l}\text { Seismic } \\
\text { Station }\end{array}$ & Location & \multicolumn{2}{l}{$\begin{array}{l}\text { Altitude } \\
{[\mathrm{m} . \mathrm{a} . \mathrm{l} .1]}\end{array}$} & $\begin{array}{l}\text { Frequency band } \\
{[\mathrm{Hz}]}\end{array}$ \\
\cline { 2 - 3 } & Latitude $\left[{ }^{\circ} \mathrm{S}\right]$ & Longitude $\left[{ }^{\circ} \mathrm{W}\right]$ & & \\
\hline AD2 & 35.148 & 70.474 & 2061 & {$[2 ; 40]$} \\
TEN & 35.167 & 70.504 & 2264 & {$[3 ; 25]$} \\
CRI & 35.1905 & 70.524 & 2909 & {$[3 ; 30]$} \\
PV01 & 35.251 & 70.503 & 2454 & {$[5 ; 25]$} \\
PV02 & 35.2477 & 70.4902 & 2427 & {$[3 ; 40]$} \\
PV03 & 35.2568 & 70.5023 & 2448 & {$[3 ; 40]$} \\
PV04 & 35.255 & 70.5123 & 2474 & {$[5 ; 40]$} \\
PV05 & 35.2482 & 70.5105 & 2495 & {$[7 ; 40]$} \\
PV06 & 35.2475 & 70.5033 & 2476 & {$[5 ; 40]$} \\
\hline
\end{tabular}

interpretation of the subsurface underneath each station, only highamplitude arrivals in the results are interpreted as potential reflectors, even though we expect that several layers are most probably present at other times. As an example, Fig. 8 shows the SI results and the candidates to subsurface reflectors for the CRI station (Fig. 8a) and for the PV01 station (Fig. 8b). The identified features are used further to interpret the subsurface structures of the area.

\section{Interpretation and discussion}

The SI results per station suggest similar main subsurface structures for the area occupied by the PV-array, and also for the OVDAS array, as expected based on the geological information provided for the area (González and Vergara 1962, Godoy et al., 1999; Charrier et al., 2002; Giambiagi et al., 2003; Silvestro et al., 2005; Fock et al., 2006; Giambiagi et al., 2009; Tapia Silva, 2010).

As the obtained results are to be compared to the geological information already available for the area, depth values are required to interpret the subsurface structures. Using the P-wave velocity model employed in the relocation process (see the previous subsection 4.a -Application and Results. Pre-processing), we transform the two-way travel times of the retrieved seismic results to depth values. Despite the fact that more accurate depth values would be obtained if a velocity model would have been developed exclusively for the area enclosed by the stations, the selected P-wave velocity model has shown to provide a good estimate of the velocities for the area as seismic sources are located properly in relation to the known geological features of the area (Olivera Craig, 2018; Volcanic Activity Reports, OVDAS-SERNAGEOMIN, Chile).

The utilized range of frequencies affects the accurate identification of adjacent subsurface layers located close in depth (or, seismic 

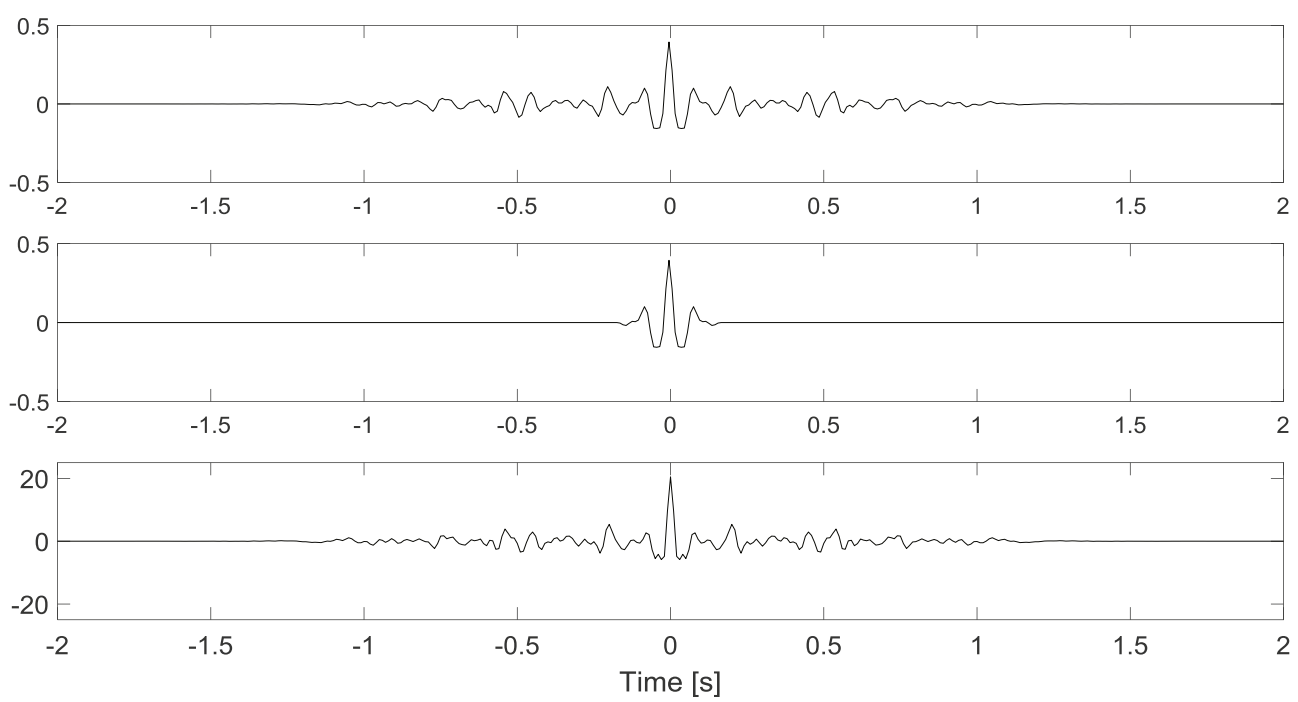

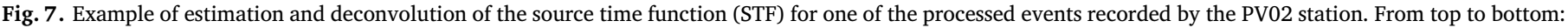
Input (autocorrelation) trace, estimated STF, and deconvolved trace.

reflection energy arriving with a small time difference at a station). To interpret two reflectors in a seismic section as separate reflectors, they should be separated by at least $1 / 4$ of the characteristic wavelength (Widess, 1973). Using the useful range of frequencies for the stations (see Table 1), we take a predominant frequency of $19 \mathrm{~Hz}$. For the Pwave velocity model used for the relocation, the average P-wave velocity at the relevant depths is $5500 \mathrm{~m} / \mathrm{s}$. This means that the predominant wavelength is $\sim 295 \mathrm{~m}$ and, thus, the predominant resolution is $72 \mathrm{~m}$.

The identification of a subsurface reflector comprises an analysis of the amplitudes of the waveform arrivals. A subsurface reflector must fulfill the following criteria: present a high-amplitude arrival in the results (i.e., a local maximum of the absolute values of the waveforms), and agree with the available geological information (i.e., to the estimated depth and slope of the subsurface structures). Note that, provided the (sub) vertical incidence of the P-wave energy, the first requirement we pose constitutes a filter for the attenuated arrivals (i.e., scattered waves and inter-bed multiples), as most of the P-wave energy ( $\sim 90 \%)$ is transmitted through impedance contacts (Shuey, 1985). Then, primary P-wave reflection arrivals are expected to be dominant in the results. Fig. 9 shows the SI results for the stations of each array (i.e., the estimated reflection response, $\left.R_{v}(t)\right)$ organized according to their location, i.e., from west to east; the shaded areas indicate the reflectors we interpret underneath each station.

We perform a comparative analysis between the depth of the interpreted subsurface structures and those indicated in the conceptual subsurface model proposed for the area of the PPVC (see Fig. 10). This application allows the interpretation of a maximum number of six impedance contrasts down to $\sim 4 \mathrm{~km}$ depth for each of the arrays. Based on the known geological features of the area and considering the altitude of the stations, Fig. 10 a and Fig. 10 b show the depth (related to the mean sea level) of the interpreted contacts underneath the PV and the OVDAS arrays, respectively (shown previously in Fig. 9); black lines track the same interpreted contact, dashed lines show a higher ambiguity in the interpretation, the height of the rectangles indicate the width of the pulse defining the local-maximum amplitude in the results.

The relatively small inter-station distance allows a joint interpretation of the subsurface structure for the PV array (Fig. 10a). Based on the interpretation rules we set up above, we interpret six impedance reflectors below the PV array, labeled A to F from shallow to deep in Fig. 10 a. In the figure, we see that the reflectors we interpret follow the trend of the proposed geological model. Even though dipping subsurface reflectors decrease the reflection energy arriving at the surface, they are clearly interpreted in the subsurface of the PV array, suggesting the contacts to be locally horizontal below the stations. We interpret the contacts to be constituted by alternating slanted and horizontal sections.

The results not only support the geological features in the proposed regional model, but they also provide an estimate (local) depth for several geological contacts. The insufficient information about the seismic velocity distribution for the first kilometers of the subsurface impedes an accurate analysis of the impedance contrast. Nevertheless, based on the known lithology of the relevant geological units, their likely velocity values (Kearey and Brooks, 1991), and the limited available information of seismic velocities in the area (Bohm et al., 2002; Casas et al., 2018), we estimate the P-wave velocity distribution in depth. Table 2 describes the lithology and average density for the geological units relevant to the depth of analysis (Benavente Zolezzi, 2010), as well as estimated P-wave velocity values, and impedances. The impedance contrast in depth would explain the reflectors C, D, E, and F, shown in Fig. 10 a. Discontinuities C and D are related to significant amount of gypsum $\left(\rho=2.3 \mathrm{gr} / \mathrm{cm}^{3}\right)$ between the Vega Negra $\left(\rho=2.8 \mathrm{gr} / \mathrm{cm}^{3}\right)$ and the Valle Grande $\left(\rho=2.7 \mathrm{gr} / \mathrm{cm}^{3}\right)$ geological units, $\mathrm{E}$ is the contact between the Valle Grande and the Lotena (its shallower section has a density of $2.4 \mathrm{gr} / \mathrm{cm}^{3}$ ) units, and $\mathrm{F}$ is the contact between the shallower section of the Lotena unit and its deeper section $\left(\rho=2.8 \mathrm{gr} / \mathrm{cm}^{3}\right)$. The shallower unit of the area is the Vega Negra, composed of sedimentary rocks. The impedance contrasts $\mathrm{A}$ and $\mathrm{B}$ would correspond to intra-unit discontinuities. Despite the available geological information states that there should not be high-density contrasts within The Vega Negra unit, sufficiently strong impedance contrasts could result in the retrieved amplitudes due to intra-unit velocity variations. Furthermore, the shallow reflectors will result in more free-surface multiples being present inside the processing time windows chosen for autocorrelation, meaning that retrieved shallow reflections might have relatively stronger apparent amplitude than retrieved deeper reflections, for which only a small number of free-surface multiples might be present in the chosen time windows.

For the OVDAS array, the larger inter-station distance impedes an accurate association of the subsurface features inferred at different stations. Therefore, the interpretation in Fig. $10 \mathrm{~b}$ is performed by station. The results of AD2 and TEN stations are consistent to those interpreted for the PV stations, which is expected based on their similar longitudes and the little geological changes in $\sim 6 \mathrm{~km}$ in latitude for the processing dominant P-wave wavelength $(\sim 295 \mathrm{~m})$. The AD2 results support the presence of two intra-unit contacts in the Vega Negra unit 
(a)

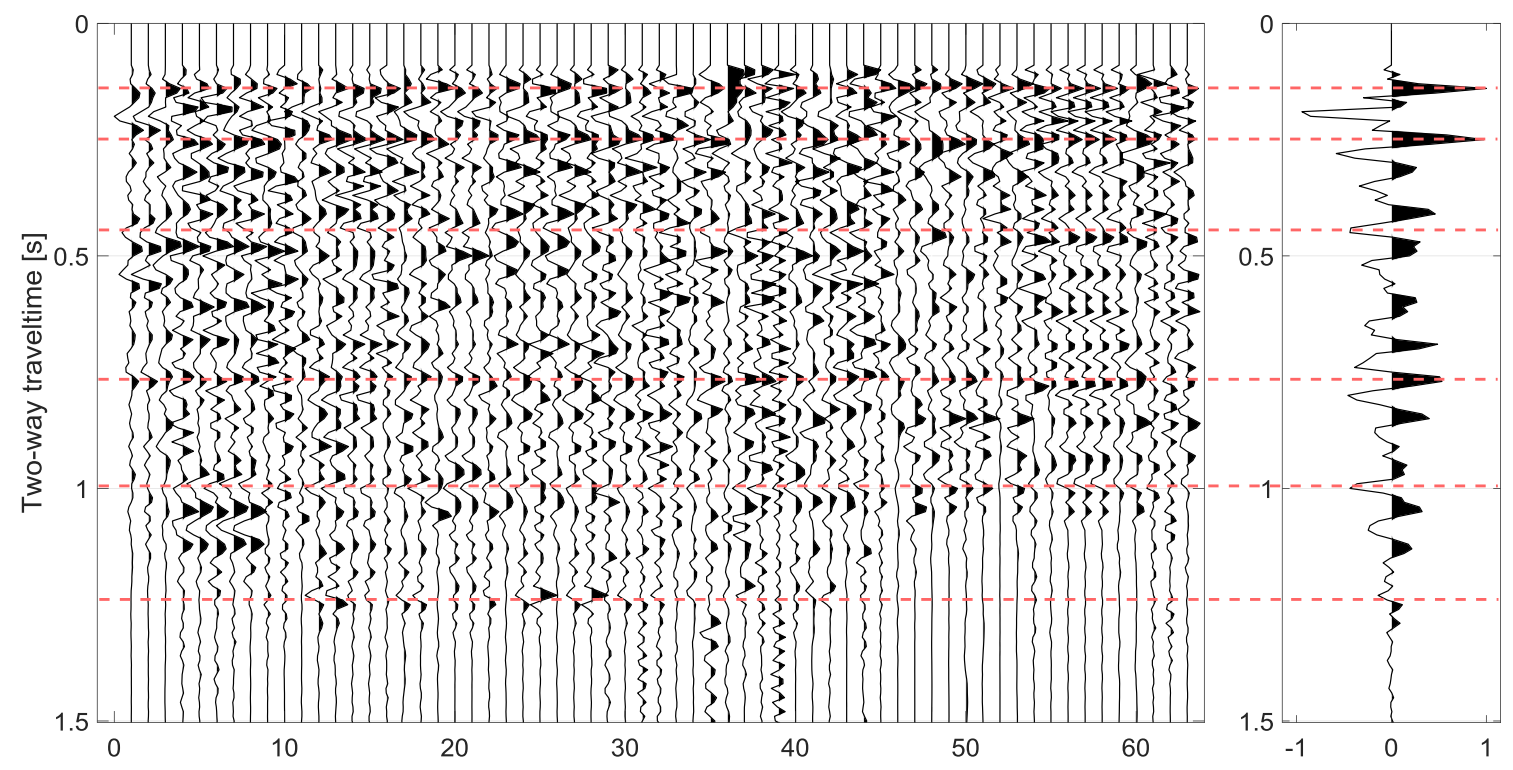

(b)

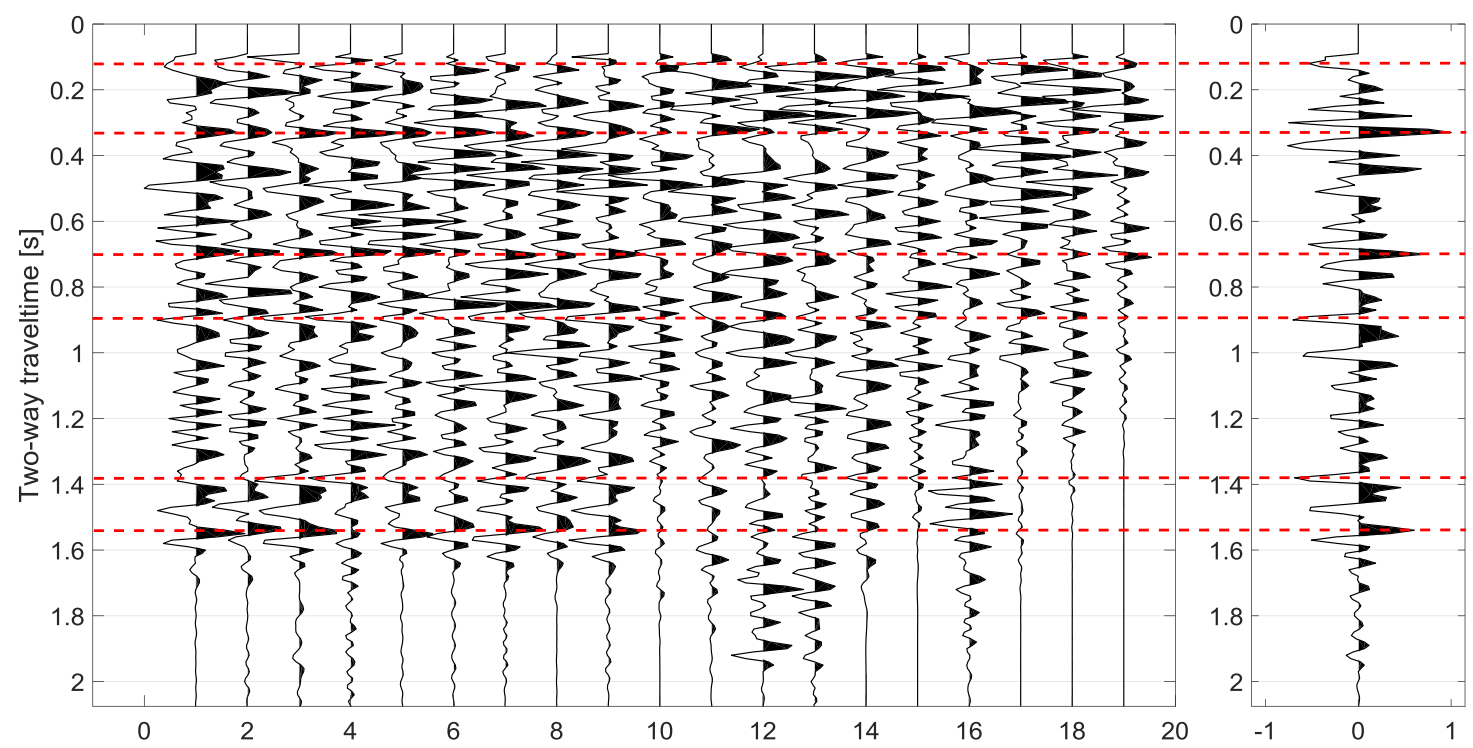

Fig. 8. Pre-stack panel (processed events) and stack for the CRI station (in a) and PV01 station (in b). Vertical axis stands for two-way travel time. Horizontal dashed lines exhibit interpreted main reflectors in the subsurface underneath the station.

(A and B), its contact with the gypsum layer (C), the contact between the latter and the Valle Grande unit (D), and the Valle Grande with the Lotena unit (E).

The TEN results show the presence of the two observed intra-unit contacts (A and B), and the contact between the Vega Negra and the gypsum layer (C). A remarkable feature in the TEN results is the lack of dominant amplitudes for depths greater than $1.8 \mathrm{~km}$. This feature could be caused by a local increase of the slope of the layers in depth, causing the seismic energy to be reflected with an angle instead of (sub) vertically and thus not reaching the station at the surface from these depths. Another factor could be the presence of the Valle Hermoso fault (see in Fig. 2), which provides a local secondary permeability causing a flow of high-temperature fluids through the Valle Grande unit (Benavente Zolezzi, 2010), and, consequently, increasing the intrinsic attenuation of the propagating seismic energy. Furthermore, the vergence of the Valle Hermoso fault favors the fluid flow to the east (Benavente Zolezzi, 2010), providing an asymmetric intrinsic-attenuation effect, i.e., greater to the east. This effect would be greater in the northern part, since the results for the PV array (at the south) are not apparently affected.
The CRI station is the closer one to the Peteroa volcano; its results show new impedance contrasts, i.e., G and F in Fig. 10 b. This figure shows three interpreted reflectors, indicated as $\mathrm{G}$, inside the first unit of the subsurface at the location of the CRI station, the Valle Grande unit. The location of $\mathrm{G}$ is characterized by complex geochemical processes comprising separation of cold and hot waters, as well as boiling and segregation of liquids and gases at temperatures around $350{ }^{\circ} \mathrm{C}$ (Benavente Zolezzi, 2010). These processes produce local changes in the subsurface conditions, i.e., spatial density variations caused by differential saturation percentages and the nature of the saturating fluid (Pola et al., 2012). Therefore, a change in the subsurface impedance distribution might arise. Furthermore, the shallow location of the Valle Grande at this longitude might favor the identification of intra-unit impedance contrasts. Fig. $10 \mathrm{~b}$ also shows two impedance contrasts between 0 and $1 \mathrm{~km}$ depth. The presence of the Valle Hermoso fault increases the complexity of the results, and so the ambiguity in the interpretation. We interpret these two impedance contrasts as the contacts between the Valle Grande and the Lotena units (reflector E) and between the shallower and deeper sections of the Lotena unit 
(a)

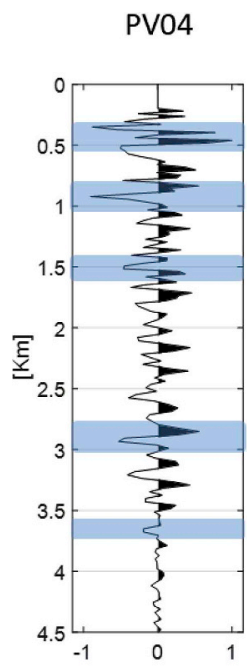

PV05

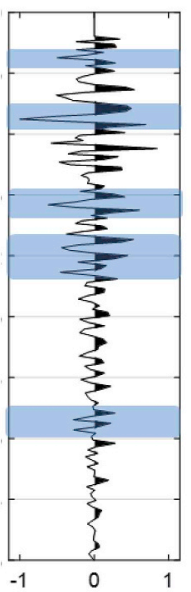

PV06

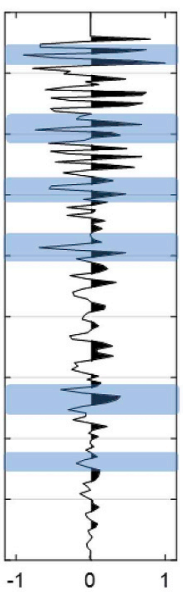

PV01

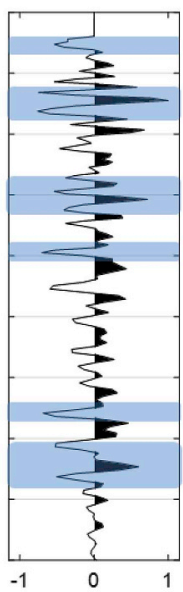

PV03

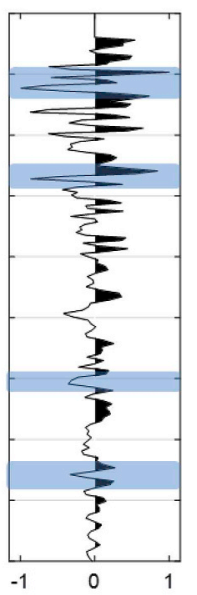

PV02

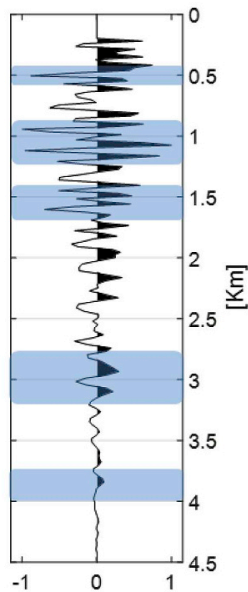

(b)

CRI

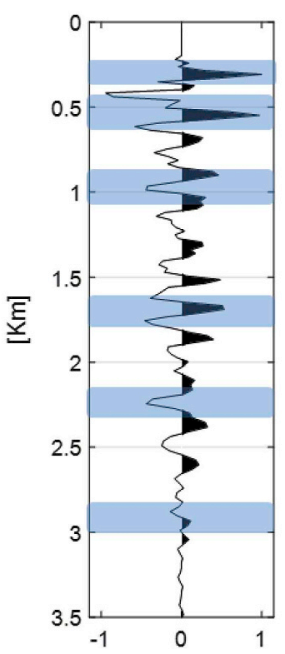

TEN

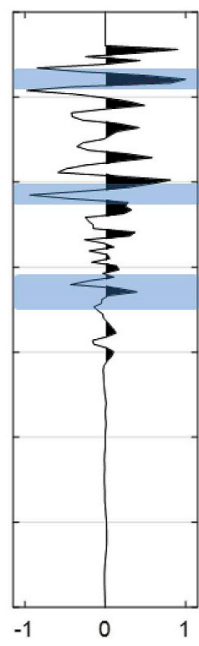

AD2

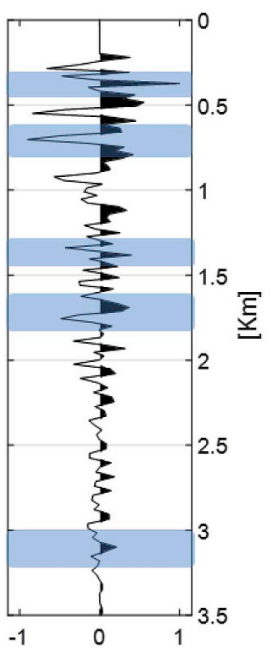

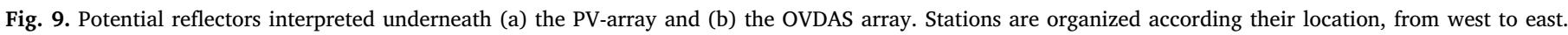
Shaded areas exhibit the depth of the interpreted layer contacts below each station. Depth values are referred to the surface at each station location.

(reflector F). Nevertheless, more information is required to confirm this interpretation. The CRI results also evidence a reflector at $\sim 4 \mathrm{~km}$ depth (from the summit of the volcano, i.e., about $-0.2 \mathrm{~km}$ a.s.l), i.e., contact $\mathrm{H}$ in Fig. $10 \mathrm{~b}$. This feature might be interpreted as the contact between the Lotena and the Grupo Cuyo geological units, in case the contact would be shallower than estimated (Tapia Silva, 2010; Benavente Zolezzi, 2010). Nevertheless, such interpretation is unlikely, as the density and the lithology of these two units would not define a sufficiently high impedance contrast to be detected in the results, provided the frequency range of processing and the depth of the contact. We infer two possible interpretations. One hypothesis is the presence of solidified magmatic material. The density and seismic-velocity variation caused by even a small volume of solidified magmatic material would define an impedance variation sufficiently great to be distinguished in the results. The second hypothesis suggests that the impedance variation is caused by a sufficiently large magma body at depth. Both hypothesis are consistent with the geological model developed for the area (Benavente Zolezzi, 2010). However, complementary research (as, for example, seismic tomography and seismic attenuation studies) are required to accurately understand the detected subsurface reflectors.

One of the advantages of the applied methodology is its simple and invariant implementation for different recording periods, providing exceptional information to understand the evolution of the magmatic systems at different time scales. Another advantages are: its independence of the amount and distribution of stations, as the workflow is applied station by station; the robustness of the processing sequence because just some minor changes on the workflow are expected to be applied in the case of a different volcano, station distribution, and/or recording period. All these properties make SI by autocorrelation easily exportable to almost every volcano of the world.

\section{Conclusions}

We used local-earthquake data recorded around the Peteroa volcano by three stations in Chile and six in Argentina to apply seismic interferometry by autocorrelation for retrieval of reflections. As only P-wave energy arriving (sub) vertically to the stations is required for this application, previously relocated events were used for Chilean stations while very local earthquakes had to be used for the stations installed in Argentina. We used the retrieved zero-offset reflection traces to interpret potential reflectors in the subsurface underneath each station. The depth of the reflectors was estimated by the usage of a P-wave velocity model adopted for the previous relocation of the events. These potential reflectors are used to interpret the main subsurface reflecting 

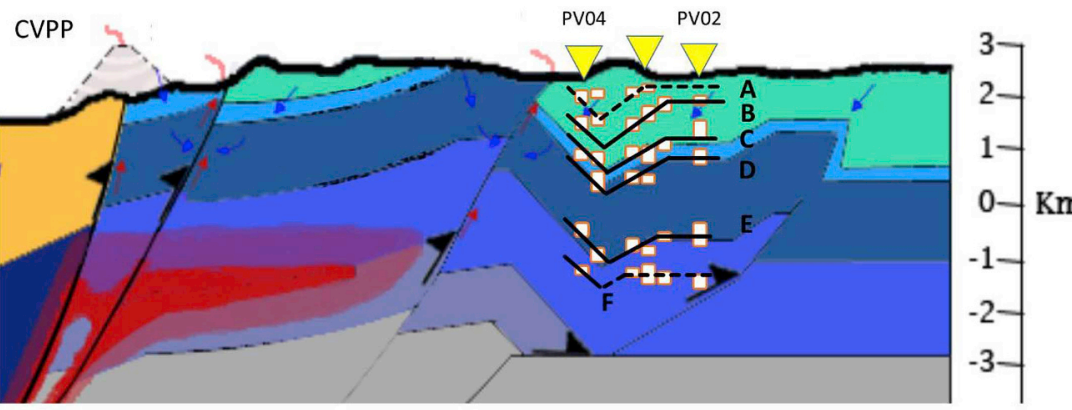

(b)

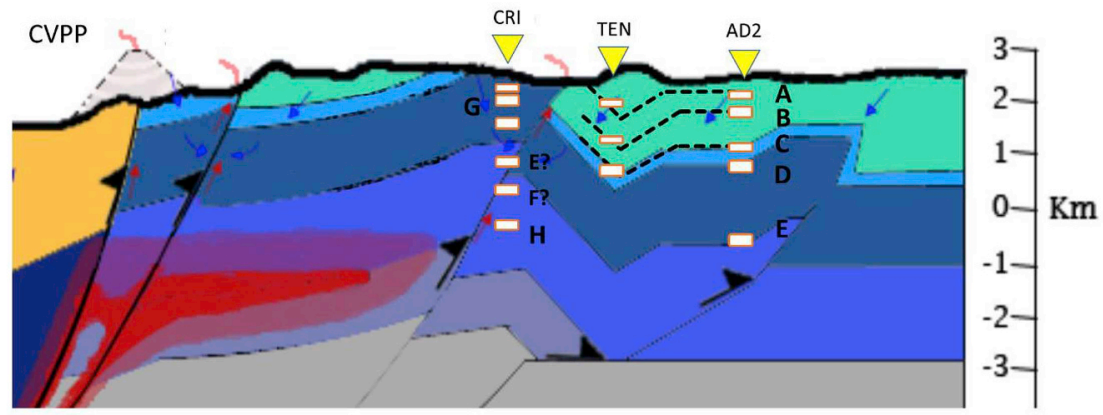

Fig. 10. Subsurface structure interpreted for the area of the (a) PV array and (b) the OVDAS array overlaid on the geological model proposed for the area (Benavente Zolezzi, 2010). Depth values are associated to the mean sea level. A-H indicate the location of the interpreted subsurface contacts. Note that $\mathrm{G}$ and $\mathrm{H}$ are only labeled in (b). Black lines track the same reflector; dashed lines identify a higher ambiguity in the interpretation; the height of each rectangle is the width of the seismic pulse related to the local maximum amplitude.

Table 2

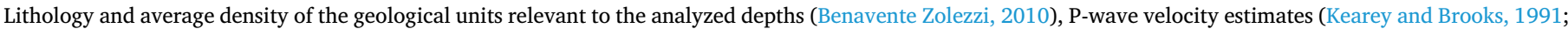
Bohm et al., 2002; Casas et al., 2018), and inferred impedances.

\begin{tabular}{|c|c|c|c|c|}
\hline Geological Unit & Lithology & Density $\rho\left(\mathrm{gr} / \mathrm{cm}^{3}\right)$ & Velocity V (km/s) & Impedance $(\rho . V)$ \\
\hline Vega Negra & Conglomerates and breccia. Sandstone and siltstones embedded & 2.8 & $\sim 1$ & 2.8 \\
\hline Gypsum & & $\sim 2.4$ & $\sim 3$ & 7.2 \\
\hline Valle Grande & Clastic sedimentary rocks, and gypsum with limestone & 2.7 & $\sim 3.5$ & 9.5 \\
\hline \multirow[t]{2}{*}{ Lotena } & Gypsum with siltstones embedded. & $\sim 2.4$ & $\sim 3.5$ & 8.4 \\
\hline & Conglomerates, sandstones, clay rocks. Then, limestone, limestone breccia, and sandstone. & 2.8 & $\sim 4.5$ & 12.6 \\
\hline Grupo Cuyo & Shale, sandstone, and limestone & $\sim 2.8$ & $\sim 4.5$ & 12.6 \\
\hline
\end{tabular}

boundaries down to about $4 \mathrm{~km}$ from the surface. The interpreted subsurface structures are in agreement with previous geological results. We provide an accurate estimation of the depth of the main subsurface layers (i.e., the Vega Negra unit, the gypsum layer, the Valle Grande unit, and the Lotena unit), and also intra-layers in the Vega Negra and Valle Grande units, in three dimensions. Furthermore, our results provide information about the location of heterogeneous areas caused by complex geochemical processes and the location of the Valle Hermoso fault. The results also support the emplacement of a magma body to about $4 \mathrm{~km}$ depth at the eastern flank of the active volcano. This study obtained the closest-ever seismic characterization of the subsurface structure to the Peteroa volcano.

\section{Acknowledgments}

The authors thank SERNAGEOMIN for providing earthquake data recorded by the OVDAS seismic network. The authors thank IRIS-PASSCAL for providing the seismic equipment deployed in Argentina, and the Argentine Ministry of Science, Technology and Production Innovation for the financial support connected to the transportation of the equipment. The authors also thank Pierre Auger Observatory and the Department of Civil Defense of Malarguie for the help during the data acquisition.

\section{Appendix A. Supplementary data}

Supplementary data to this article can be found online at https:// doi.org/10.1016/j.jsames.2019.03.012.

\section{References}

Aguilera, F., Benavente, O., Gutiérrez, F., Romero, J., Saltori, O., González, R., Agusto, M., Kaselli, A., Pizarro, M., 2016. Eruptive activity of Planchón-Peteroa volcano for period 2010-2011, southern Andean volcanic zone, Chile. Andean Geol. 43 (1), 20-46. https://doi.org/10.5027/andgeoV43n1-a02. January, 2016.

Agusto, M., Lamberti, M.C., Núñez, N., Sánchez, H., García, S., Gómez, M., 2017. Primeros datos de desgasificación difusa de $\mathrm{CO}_{2}$ de la caldera del Volcán Planchón Peteroa. In: Proceedings of the XII Meeting of the International Center for Earth Sciences, vol. 103 ISBN 978-987-1323-49-4.

Benavente Zolezzi, O., 2010. Actividad Hidrotermal Asociada a Los Complejos Volcánicos Planchón-Peteroa Y Descabezado Grande-Quizapu-Cerro Azul, $36^{\circ} \mathrm{S}$ Y $37^{\circ} \mathrm{S}$, Zona Volcánica Sur, Chile. Memoria para optar al título de geólogo. Universidad de Chile, pp. 204.

Bohm, M., Lüth, S., Hechtler, H., Asch, G., Bataille, K., Bruhn, C., Rietbrock, A., Wigger, P., 2002. The Southern Andes between $36^{\circ} \mathrm{S}$ and $40^{\circ} \mathrm{S}$ latitude: seismicity and average velocities. Tectonophysics 356, 275-289.

Boullenger, B., Verdel, A., Paap, B., Thorbecke, J., Draganov, D., 2014. Studying CO2 storage with ambient-noise seismic interferometry: a combined numerical feasibility study and field-data example for Ketzin, Germany. Geophysics 80 (1), Q1-Q13.

Brenguier, F., Campillo, M., Hadziioannou, C., Shapiro, N.M., Larose, E., 2008. Postseismic relaxation along the San Andreas fault at Parkfield from continuous seismological observations. Science 321, 1478-1481.

Casas, J.A., Badi, G., Manassero, M.C., Gomez, P., Draganov, D., Ruzzante, J., 2014 Characterization of seismo-volcanic activity in Peteroa volcano, Central Andes Argentina-Chile (July, 2014). Earth Sci. Res. J. 18, 335-336 1794-6190.

Casas, J.A., Mikesell, T.D., Draganov, D., Lepore, S., Badi, G.A., Franco, L., Gomez, M., 2018. Shallow S-wave velocity structure from ambient seismic noise at PlanchonPeteroa volcanic complex, Argentina-Chile. Bull. Seismol. Soc. Am. 108 (4), 2183-2198.

Cembrano, J., Lara, L., 2009. The link between volcanism and tectonics in the southern volcanic zone of the Chilean Andes: a review. Tectonophysics 471 (1-2), 96-113.

Charrier, R., Baeza, O., Elgueta, S., Flynn, J.J., Gans, P., Kay, S.M., Muñoz, N., Wyss, A.R. Zurita, E., 2002. Evidence for Cenozoic extensional basin development and tectonic 
inversion south of the flat-slab segment, southern Central Andes, Chile (33-36 SL). J. South Am. Earth Sci. 15 (1), 117-139.

Chouet, B., 2003. Volcano seismology. Pure Appl. Geophys. 160, 739-788.

Claerbout, J., 1968. Synthesis of a layered medium from its acoustic transmission response. Geophysics 33, 264-269.

Draganov, D., Wapenaar, K., Thorbecke, J., Nishizawa, O., 2007. Retrieving reflection responses by crosscorrelating transmission responses from deterministic transient sources: application to ultrasonic data. J. Acoust. Soc. Am. 122, EL172. https://doi. $\operatorname{org} / 10.1121 / 1.2794864$.

Fan, Y., Snieder, R., 2009. Required source distribution for interferometry of waves and diffusive fields. Geophys. J. Int. 179 (2), 1232-1244.

Fock, A., Charrier, R., Farías, M., Muñoz, M., 2006. Fallas de vergencia oeste en la Cordillera Principal de Chile Central: inversión de la cuenca de Abanico (33-34 S). Revista de la Asociación Geológica Argentina, Publicación Especial 6, 48-55.

Giambiagi, L.B., Ramos, V.A., Godoy, E., Alvarez, P.P., Orts, S., 2003. Cenozoic deformation and tectonic style of the Andes, between 33 and 34 south latitude. Tectonics 22 (4).

Giambiagi, L., Ghiglione, M., Cristallini, E., Bottesi, G., 2009. Kinematic models of basement/cover interaction: insights from the Malargüe fold and thrust belt, Mendoza, Argentina. J. Struct. Geol. 31 (12), 1443-1457.

Gill, J.B., 1981. Orogenic Andesites and Plate Tectonics. Springer-Verlag, New York.

Godoy, E., Yáñez, G., Vera, E., 1999. Inversion of an Oligocene volcano-tectonic basin and uplifting of its superimposed Miocene magmatic arc in the Chilean Central Andes: first seismic and gravity evidences. Tectonophysics 306 (2), 217-236.

González, O., Vergara, M., 1962. Reconocimiento geológico de la Cordillera de los Andes entre los paralelos $35^{\circ}$ y $38^{\circ} \mathrm{S}$. Instituto Geología, Universidad de Chile, Santiago, pp. 24.

Gorbatov, A., Saygin, E., Kennett, B.L.N., 2013. Crustal properties from seismic station autocorrelograms. Geophys. J. Int. 192 (2), 861-870.

Haller, M.J., Risso, C., 2011. La erupción del Volcán Peteroa (3515'S, $\left.70^{\circ} 18^{\prime} \mathrm{O}\right)$ del 4 de septiembre de 2010. Rev. Asoc. Geol. Argent. 68 (2), 295-305.

Haller, M.J., Ostera, H.A., Pesce, A.H., Gardini, M., Folgueras, A., 1994. Vulcanoestratigrafía reciente y eruptividad del volcán Peteroa. In: Congreso Geológico Chileno, N 7, Concepción, Actas 1, pp. 319-323.

Husen, S., Hardebeck, J.L., 2010. Earthquake Location Accuracy. Community Online Resource for Statistical Seismicity Analysishttps://doi.org/10.5078/corssa55815573.

Kearey, P., Brooks, M., 1991. An Introduction to Geophysical Prospecting. Blackwell, Boston.

Kim, D., Brown, L.D., Árnason, K., Águstsson, K., Blanck, H., 2017. Magma reflection imaging in Krafla, Iceland, using microearthquake sources. J. Geophys. Res. Solid Earth 122, 5228-5242. https://doi.org/10.1002/2016JB013809.

López-Escobar, L., Cembrano, J., Moreno, H., 1995. Geochemistry and tectonics of the Chilean southern Andes basaltic quaternary volcanism (37-46 $\left.{ }^{\circ} \mathrm{S}\right)$. Rev. Geol. Chile 22 (2), 219-234. https://doi.org/10.5027/andgeoV22n2-a06.

Nakata, N., Snieder, R., Tsuji, T., Larner, K., Matsuoka, T., 2011. Shear wave imaging from traffic noise using seismic interferometry by cross-coherence. Geophysics 76, SA97-SA106.

Naranjo, J., 2012. Principales etapas evolutivas holocenas del volcán Planchón y su reactivación relacionada al megasismo del 27 de Febrero de 2010. In: Congreso Geológico Chileno, pp. 440-441 (No. 13.

Nishitsuji, Y., Ruigrok, E., Gomez, M., Draganov, D., 2014. Global-phase H/V spectral ratio for imaging the basin in the Malargüe region, Argentina. Seismol Res. Lett. 85, 1004-1011. https://doi.org/10.1785/0220140054.

Nishitsuji, Y., Rowe, C., Wapenaar, K., Draganov, D., 2016. Reflection imaging of the moon's interior using deep-moonquake seismic interferometry. J. Geophys. Res. Planets 121, 695-713. https://doi.org/10.1002/2015JE004975.

Nishitsuji, Y., Ruigrok, E., Gomez, M., Wapenaar, K., Draganov, D., 2016a. Reflection imaging of Aseismic zones of the Nazca slab by global-phase seismic interferometry. Interpretation 4https://doi.org/10.1190/INT-2015-0225.1. SJ1-SJ16.

Olivera Craig, 2018. Relocation of Fracture Seismicity in Planchón-Peteroa Volcanic Complex through Optimization of the Arrival-Times Identification and Joint Location Techniques. Graduate Thesis. FCAGLP-UNLP, Argentina.

Oren, Can, Nowack, Robert L., 1 January 2017. Seismic body-wave interferometry using noise autocorrelations for crustal structure. Geophys. J. Int. 208 (1), 321-332. https://doi.org/10.1093/gji/ggw394.

Pola, A., Crosta, G., Fusi, N., Barberini, V., Norini, G., 2012. Influence of alteration on physical properties of volcanic rocks. Tectonophysics 566, 67-86.

Raponi, M., García, S., Gómez, M., Agusto, M., 2017. Mediciones remotas de SO2 en el Complejo Volcánico Planchón-Peteroa, empleando un sistema DOAS portable. In: Proceedings of the XII Meeting of the International Center for Earth Sciences, vol. 83 ISBN 978-987-1323-49-4.

Ruigrok, E., Wapenaar, K., 2012. Global-phase seismic interferometry unveils P-wave reflectivity below the Himalayas and Tibet. Geophys. Res. Lett. 39, L11303. https:// doi.org/10.1029/2012GL051672.

Ruigrok, E., Draganov, D., Gomez, M.P., Ruzzante, J., Torres, D., Lopes Pumarega, I., Barbero, N., Ramires, A., Castano Ganan, A.R., van Wijk, K., Wapenaar, K., 2012. Malargüe seismic array: design and deployment for the temporary array. Eur. Phys. J. Plus 127. https://doi.org/10.1140/epjp/i2012012126-7.

Schuster, G.T., 2009. Seismic Interferometry. Cambridge Univ. Press 13.978-0-51154011-0.

Sens-Schönfelder, C., Wegler, U., 2006. Passive image interferometry and seasonal variations of seismic velocities at Merapi Volcano, Indonesia. Geophys. Res. Lett. 33, L21302.

Shuey, R.T., 1985. A simplification of the Zoeppritz equations. Geophysics 50 (4), 609-614.

Silvestro, J., Kraemer, P., Achilli, F., Brinkworth, W., 2005. Evolución de las cuencas sinorogénicas de la Cordillera Principal entre 35-36 S, Malargüe. Rev. Asoc. Geol. Argent. 60 (4), 627-643.

Snieder, R., 2004. Extracting the Green's function from the correlation of coda waves: a derivation based on stationary phase. Phys. Rev. E 69 (4). https://doi.org/10.1103/ PhysRevE.69.046610.

Tapia Silva, F., 2010. Análisis estructural del sector Occidental de la Faja Plegada y Corrida de Malargüe en el curso superior del río Colorado de Lontué $\left(35^{\circ} 18^{\prime}\right.$ y $35^{\circ} 23^{\prime}$ s), Región del Maule, chile. Universidad de Chile. Memoria para optar al título de geólogo, Universidad de Chile.

Tassi, F., Aguilera, F., Benavente, O., Paonita, A., Chiodini, G., Caliro, S., Agusto, M., Gutierrez, F., Capaccioni, B., Vaselli, O., Kaselli, A., Saltori, O., 2016. Geochemistry of fluid discharges from Peteroa volcano (Argentina-Chile) in 2010-2015: insights into compositional changes related to the fluid source region(s). Chem. Geol. https:// doi.org/10.1016/j.chemgeo.2016.04.007. 2016.

Tormey, D.R., Frey, F.A., Lopez-Escobar, L., 1989. Geologic history of the active AzufrePlanchón-Peteroa Volcanic Center ( $35^{\circ} 15^{\prime}$ S, southern Andes) with implications for the development of compositional gaps. Rev. Asoc. Geol. Argent. 44 (1-4), 420-430.

Vasconcelos, I., Snieder, R., 2008a. Interferometry by deconvolution, Part 1 - theory for acoustic waves and numerical examples. Geophysics 73 (3), S115-S128.

Vasconcelos, I., Snieder, R., 2008b. Interferometry by deconvolution, Part 2 - theory for elastic waves and application to drill-bit seismic imaging. Geophysics 73, S129-S141.

Waldhauser, F., Ellsworth, W.L., 2000. A double-difference earthquake location algorithm: method and application to the northern Hayward fault, California. Bull. Seismol. Soc. Am. 90 (6), 1353-1368.

Wapenaar, K., 2003. Synthesis of an inhomogeneous medium from its acoustic transmission response. Geophysics 68, 1756-1759.

Wapenaar, K., Fokkema, J., 2006. Green's function representations for seismic interferometry. Geophysics 71 (4). https://doi.org/10.1190/1.2213955. July-August 2006.

Wapenaar, K., Draganov, D., Robertsson, J.O.A., 2008. Seismic interferometry: history and present status. Geophysics Reprint Series SEG 26 (Tulsa).

Wapenaar, K., Draganov, D., Snieder, R., Campman, X., Verdel, A., 2010. Tutorial on seismic interferometry. Part I: basic principles and applications. Geophysics 75, 75A195-75A209. https://doi.org/10.1190/1.3457445.

Wapenaar, K., Ruigrok, E., van der Neut, J., Draganov, D., 2011. Improved surface wave retrieval from ambient seismic noise by multi-dimensional deconvolution. Geophys. Res. Lett. 38, L01313.

Weemstra, K., Draganov, D., Ruigrok, E., Hunziker, J., Gomez, M., Wapenaar, K., 2017. Application of seismic interferometry by multidimensional deconvolution to ambient seismic noise recorded in Malargüe, Argentina. Geophys. J. Int. 208, 693-714. https://doi.org/10.1093/gji/ggw425.

Widess, M.B., 1973. How thin is a thin bed. Geophysics 38, 1176-1180.

Yilmaz, O., 2001. Seismic Data Analysis, second ed. SEG Publishing, Tulsa, OK. 